\title{
Bacterial Load on Cellphones of Healthcare Givers and Patient Attendants in a Tertiary Care Hospital of Odisha- A Cross Sectional Study
}

\author{
Abhishek Padhi ${ }^{1}$, Bimoch Projna Paty ${ }^{1 *}$, Sithun Patro ${ }^{2}$ and Banojini Parida ${ }^{1}$ \\ ${ }^{1}$ Department of Microbiology, ${ }^{2}$ Department of Community Medicine, \\ MKCG Medical College, India \\ *Corresponding author:
}

\begin{tabular}{|c|}
\hline Keywords \\
\hline $\begin{array}{l}\text { Cell phones, Health } \\
\text { care associated } \\
\text { infections, MRSA }\end{array}$ \\
\hline Article Info \\
\hline $\begin{array}{l}\text { Accepted: } \\
07 \text { February } 2019 \\
\text { Available Online: } \\
10 \text { March } 2019\end{array}$ \\
\hline
\end{tabular}

\section{Introduction}

Cellphones are widely used by the healthcare workers (HCWs) and non-HCWs equally in every location. With all the achievements and benefits of the mobile phone, it is easy to overlook the health hazard it might pose to its many users ${ }^{1}$. The constant handling of mobile phones by users in hospitals (by patients, visitors and HCWs, etc.) makes it an open breeding place for transmission of microorganisms, as well as health careassociated infections (HAIs). This is especially so with those associated with the skin due to the moisture and optimum temperature of human body especially our palms. Unlike our hands, which are easily disinfected using alcohol-based hand rubs (ABHRs) that are made available readily across all hospitals and medical facilities, our 
mobile phones are cumbersome to clean. We even rarely make an effort to disinfect them. As a result, these devices have the potential for contamination with various bacterial agents ${ }^{2}$.

Colonized micro-organisms on the devices of HCWs may be transmitted to patients even if patients do not have direct contact with mobile phones. These organisms if pathogenic can be detrimental to the health of the patients especially those in critical care units ${ }^{3}$. Doctors and healthcare staff working in critical areas as intensive care units (ICUs) and operating units are highly exposed to deadly microorganisms.

These mobile phones used by HCWs often become carriers and may serve as vectors and spread microorganisms wherever they are taken along ${ }^{4}$. Colonized micro-organisms on the devices of HCWs may be transmitted to patients even if patients do not have direct contact with mobile phones 5 . These organisms if pathogenic can be detrimental to the health of the patients especially those in critical care units and if the organisms transferred happen to be drug-resistant; the situation becomes even more grave as it becomes difficult to treat because of the limited drug options available $^{6}$.

Healthcare-associated infections (HAIs) are a major challenge to the healthcare system and are associated with significant mortality, morbidity, and high economic burden. It is estimated that of every 100 hospitalized patients at any given time, seven in developed and ten in developing countries will acquire at least one $\mathrm{HAI}^{7}$.Patients in intensive care units (ICUs) are particularly susceptible to HAIs because of their poor health status in addition to the use of invasive equipment like catheters and cannulae. Similarly, infants in neonatal care units (NCUs) have a higher risk of HAIs because of their immature immune systems, their skin does not provide a strong barrier against organisms in the environment and a large number of these infants are premature and often require invasive procedures to sustain their life such as mechanical ventilation and total parenteral nutrition ${ }^{8}$. Contaminated hands of healthcare providers play a major role in spreading infections in healthcare settings. Hand hygiene is one of the most important preventive interventions against the spread of infections in healthcare settings 9 .

\section{Materials and Methods}

Study Design, Sample Size and Study Setting. A cross sectional study was carried out on 96 mobile phones used by doctors, nurses, laboratory personnel and patient attendants for a period of five months from May 2018 to September 2018.

\section{Sample collection and processing}

Samples from mobile phones were collected using sterile cotton swabs. Each swab was first moistened with sterile peptone water and was rotated over the surface of both sides of the tested mobile phone together with the keypad in non touchscreen phones. All swabs were immediately streaked (surface spread) over the surface of blood and MacConkey's agar plates. The cotton ends of these swabs were cut off and soaked in $10 \mathrm{ml}$ peptone water. All inoculated blood and MacConkey's agar plates together with the inoculated peptone water tubes were transferred rapidly to the microbiology laboratory.

At the laboratory, blood and MacConkey's agar plates were incubated aerobically at $37^{\circ} \mathrm{C}$ for 24 hours. The inoculated peptone water tubes were vortexed and a one $\mathrm{ml}$ from each tube was placed in a sterile petridish, then 15 $\mathrm{ml}$ of melted plate count agar medium was poured over the sample portion. The agar was thoroughly mixed with the sample portion and 
allowed to set and solidify. The plates were then inverted and incubated aerobically at $37^{\circ} \mathrm{C}$ for 24 hours.

\section{Identification of organism}

Isolated bacterial agents were identified according to the standard microbiological methods described by Forbes et al., (2007) ${ }^{10}$. They were identified using Gram's staining, colony morphology and appropriate biochemical tests.

For identification of Gram-positive cocci (GPC); isolates that appeared as medium sized circular, white or golden yellow with smooth convex surface and entire edge and were $\beta$ hemolytic or non-hemolytic on blood agar plates and were positive for catalase, slide and tube coagulase and Voges Proskauer tests were considered as Staphylococcus aureus ( $S$. aureus).

Non-haemolytic, catalase-positive, coagulasenegative, bacitracin-sensitive GPC were identified as Micrococcus spp., while catalase-positive, coagulase-negative and bacitracin-resistant GPC were considered as coagulase-negative staphylococci (CoNS).

Staphylococcus aureus and CoNS identified isolates were further checked for their susceptibility to methicillin using oxacillin (1 $\mu \mathrm{g})$ and cefoxitin $(30 \mu \mathrm{g})$ discs on Mueller Hinton agar plates supplemented by $4 \% \mathrm{NaCl}$ by disk diffusion method described by Bauer and Kirby ${ }^{11}$. The inhibition zone diameters were measured and interpreted as recommended by the Clinical and Laboratory Standards Institute (CLSI) ${ }^{12}$.

As regards Gram-negative bacilli (lactose and non-lactose fermenters), the oxidase, catalase, triple sugar iron agar (TSI), indole, methyl red, Voges Proskauer, citrate (IMViC) and urease tests were carried out for their identification.

\section{Results and Discussion}

The present study was conducted on 96 mobile phones randomly selected from patients, patient attendants and HCWs from our hospital.

This study enrolled the mobile phones of 28 doctors (29.17\%), 21 patients $(21.87 \%), 26$ patient attendants $(27.08 \%)$ and 21 laboratory personnels (21.87\%) (Fig. 1).

Of the 96 mobile phones tested, 82 (85.4\%) showed bacterial growth from which 163 organisms were isolated. Mixed infections were seen in $64(66.7 \%)$ mobiles and pure growth was observed in $18(18.8 \%)$ mobiles.

Mixed growth was seen in 64 (78.04\%) mobiles and pure growth was observed in 18(21.96\%) mobiles (Fig. 2).

As regards the organisms isolated Coagulase negative staphylococcus were the most common isolates $(31.9 \%)$ followed by Micrococcus (20.8\%) and Staphylococcus aureus (14.7\%). Klebsiella spp. (8\%) and Candida spp. (6\%) were the least common isolates. Methicillin resistant Staphylococcus aureus accounted for $6 \%$ of the total isolates.

Of the 82 cell phones with microbial contaminations, 24 doctors $(29.26 \%), 17$ patients $(20.73 \%), 23$ patient attendants $(28.04 \%)$ and 18 laboratory personnels $(21.95 \%)$ cell phones had microbial contamination in them (Fig. 3).

Hospital acquired infection caused by multidrug-resistant organisms is a growing problem in many health care institutions $13,14,15$. Hands, instruments, mobile phones or other inanimate hospital objects used by HCWs may serve as vectors for the nosocomial transmission of microorganisms ${ }^{16,17,18}$. Unlike fixed phones, 
mobile phones are often used in these areas close to the patients and these patients are more vulnerable to hospital acquired infections ${ }^{19,20}$.

In this study, 96 mobile phones from 4 different categories of hospital population viz., doctors, patients, patient attendants and lab personnels were screened for the presence of bacterial contamination. $82(85.41 \%)$ cell phones had microbial contamination in them. Similar findings were found in a study conducted by Tambe and Pai $(2012)^{21} 83 \%$ of screened mobile phones of the HCWs showed bacterial or/and fungal contamination.

In a separate study, researchers found that 95\% of phones were contaminated with some kind of bacteria, many of which were resistant to multiple antibiotics. By also testing the participants' hands, the researchers were able to show that a significant number of germs were transferred from their hands to their phones, and vice versa. In fact, about $30 \%$ of the bacteria on the phones ended up on the owner's hands ${ }^{22}$.

CONS (31.9\%), Micrococcus (20.8\%), Staphylococcus aureus (14.7\%), Diphtheroids (10.4\%), Escherichia coli (8.4\%), Klebsiella (8\%), Candida spp. (6\%) were the organisms isolated in the present study. MRSA accounted for $6 \%$. In the study by Tagoe et al., $(2011)^{1}$ the isolated bacteria included Klebsiella pneumoniae (10\%), Citrobacter spp. (2\%), S. aureus (4\%), CoNS (15\%), Pseudomonas aeruginosa (4\%), Salmonella spp.(3\%), Shigella spp. (2\%), Proteus mirabilis (19\%), E. coli (8\%), Bacillus cereus (23\%), Streptococcus pneumoniae (10\%), Salmonella spp. (3\%) and Shigella spp. $(2 \%)$.

Tambe and Pai $(2012)^{21}$ reported that the isolation of $S$. aureus was maximum in all the categories of HCWs (54\%), followed by
Micrococci (21\%), diphtheroids (8\%), Enterococci (4\%), Pseudomonas, Citrobacter and Bacillus spp. (3\% each), Acinetobacter, Enterobacter and Streptococcus viridans (2\% each).

In a study by Bhoonderowa et al., $(2014){ }^{23}$ CoNS was the most prevalent $(69 \%)$ bacteria from mobile phones of volunteers in the community. In 2014, a study carried out by Raghavendra et al., ${ }^{24}$ revealed that $52 \%$ of the examined mobile phones of HCWs were contaminated by $S$. aureus. In this work, it has been noted that staphylococci were the most frequently encountered isolates. This pathogen is of greater concern because of its virulence, its ability to cause a diverse array of life threatening infections, and its capacity to adapt to different environmental conditions ${ }^{25}$. It is also a well-known fact that organisms like $S$. aureus and CoNS resist dryness and thus can survive and multiply rapidly in warm environments like cell phones ${ }^{26}$.

Of the 82 cell phones with microbial contaminations, 24 doctors (29.26\%), 17 patients $(20.73 \%), 23$ patient attendants $(28.04 \%)$ and 18 laboratory personnels $(21.95 \%)$ cell phones had microbial contamination in them.

A practice guideline was issued by the community and Hospital Infection Control Association (CHICA, Canada) to address the issues of electronic devices in health care settings. Some of their recommendations include that hand hygiene should be performed between patient contact and before and after accessing a device, manufacturer's guidelines for use, cleaning/disinfection and maintenance should be reviewed to ensure that these guidelines meet the standards for cleaning and low-level disinfection that are necessary for exposure to multidrug-resistant organisms $^{27}$ (Table 1 and 2). 
Table.1 Number of cell phone showing growth of microorganisms

\begin{tabular}{|l|c|c|}
\hline & Number of Cell Phones & Percentage (\%) \\
\hline GROWTH & 82 & 85.4 \\
\hline NO GROWTH & 14 & 14.6 \\
\hline
\end{tabular}

Table.2 Organisms isolated

\begin{tabular}{|l|c|c|}
\hline Organism & Number of Isolates & Percentage (\%) \\
\hline CONS & 52 & 31.9 \\
\hline Micrococcus & 34 & 20.8 \\
\hline Staphylococcus aureus & 24 & 14.7 \\
\hline Diphtheroids & 17 & 10.4 \\
\hline Candida spp. & 10 & 6.2 \\
\hline Escherichia coli & 14 & 8.4 \\
\hline Klebsiella spp. & 12 & 8.0 \\
\hline
\end{tabular}

Fig.1 Distribution of study population

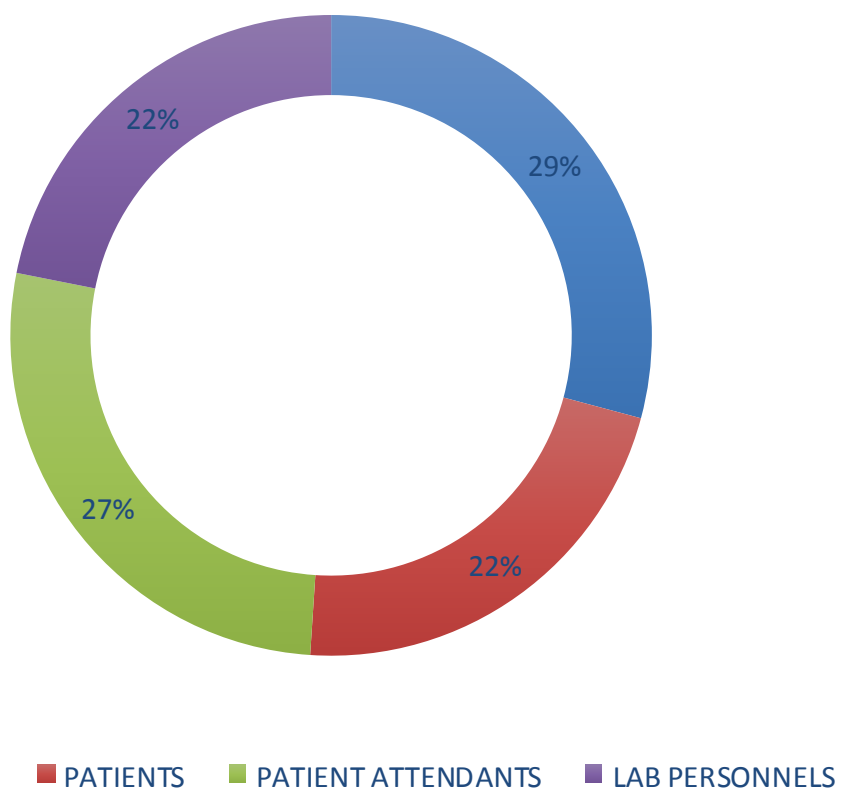


Fig.2 Mobiles with mixed growth and pure growth

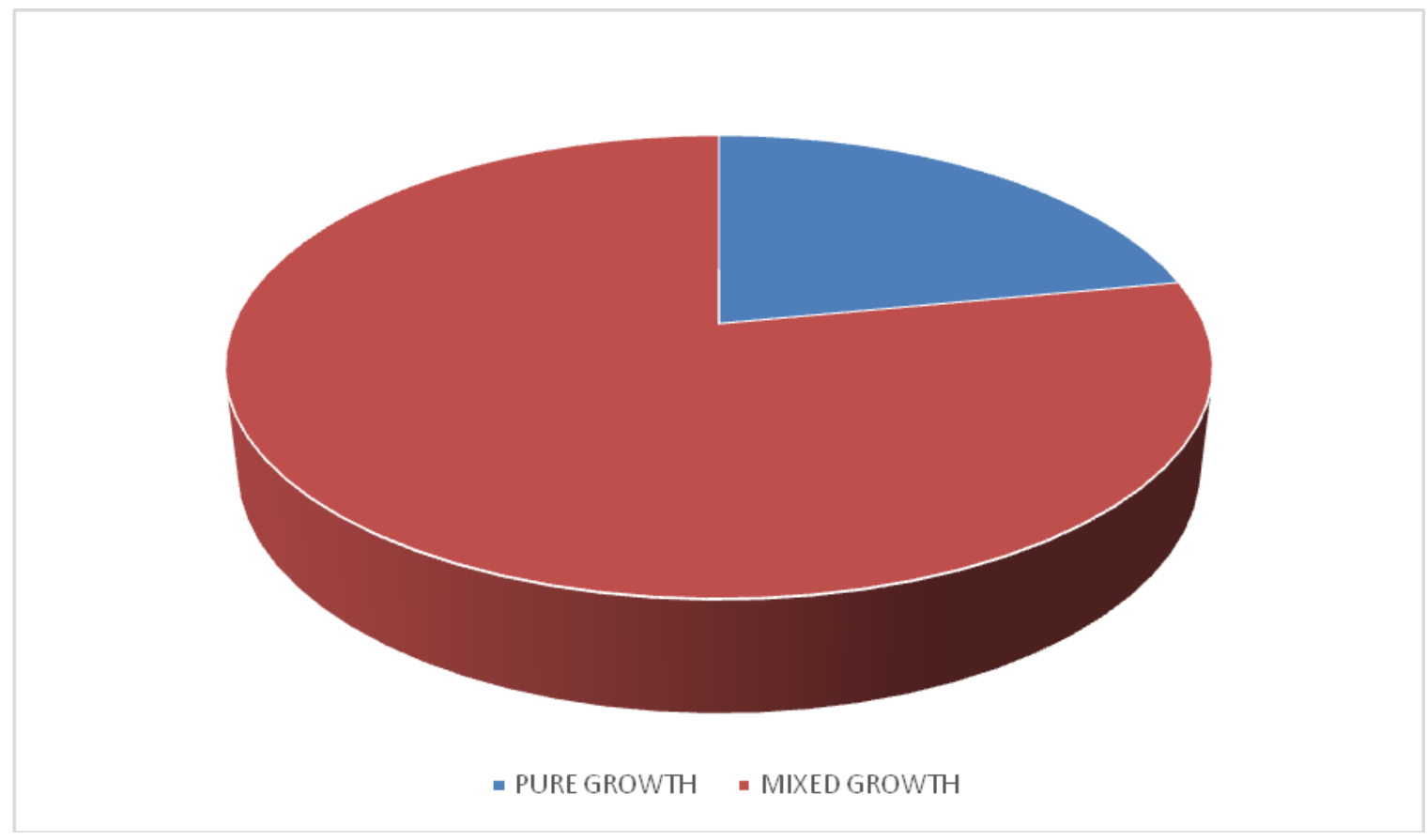

Fig.3 microbial contaminations

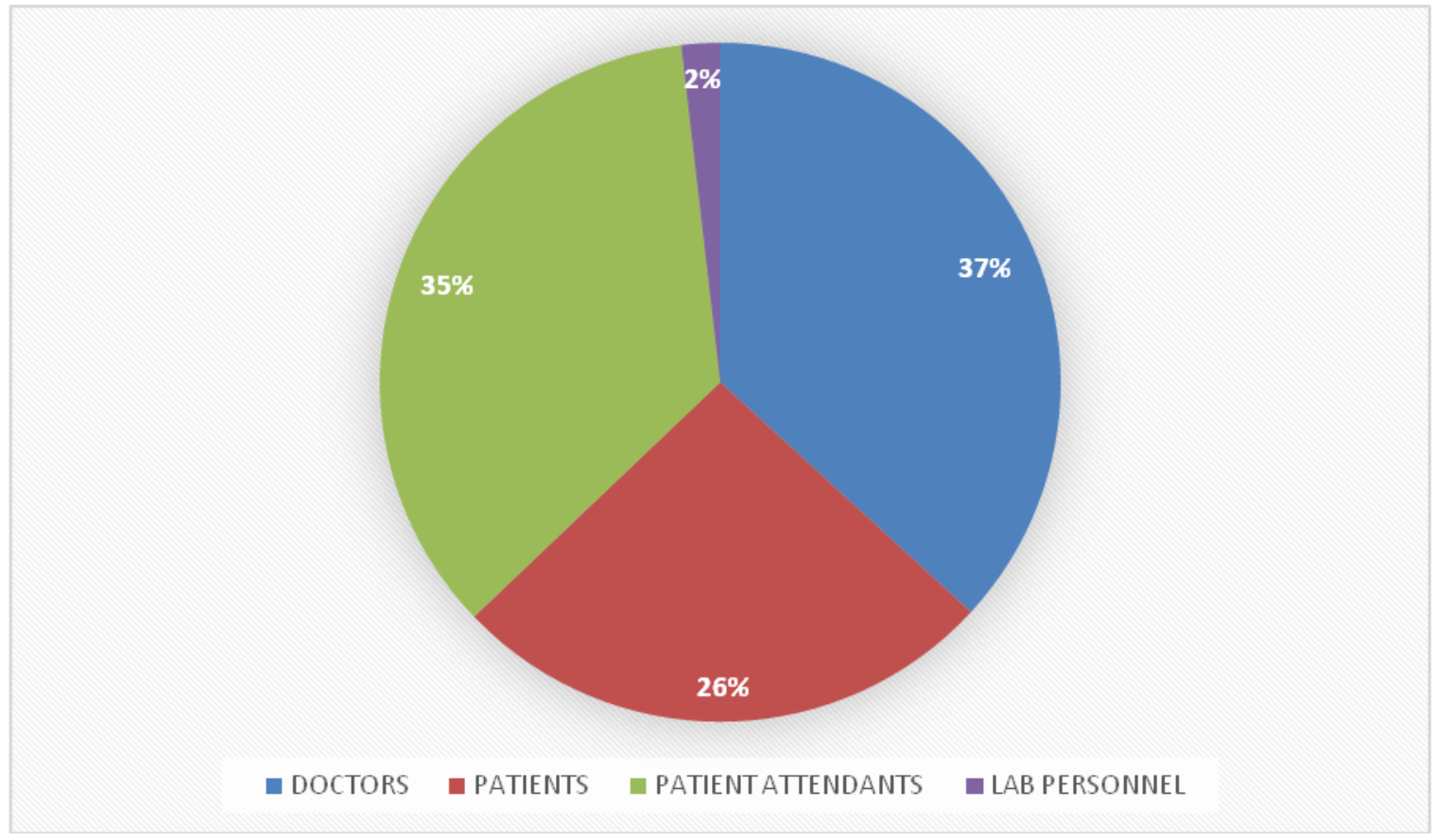

In conclusion, with the rampant use of mobile phones in healthcare settings their chances of being vehicle of transmitting pathogens especially the multidrug resistant ones has increased many fold. Isolation of MRSA and Gram-negative bacteria from mobile phones of clinicians treating patients is of a major concern, and calls for efforts to consider 
guidelines for mobile phone disinfection and its restricted use. Only minority of clinicians have ever disinfected their mobile phones, which is not an optimal practice and highlights the need to increase the awareness about mobile phones disinfection among clinicians, given that banning mobile phones in ICU settings is losing momentum. Finally, further research is needed in order to provide evidence that better mobile phone hygiene will lead to a reduction in HAIs.

\section{References}

Angadi KM, Misra R, Gupta U, Jadhav S, Sardar M. Study of the role of mobile phones in the transmission of Hospital acquired infections. Med J DY Patil Univ. 2014; 7(4): 435-438.

Angadi KM, Misra R, Gupta U, Jadhav S, Sardar M. Study of the role of mobile phones in the transmission of Hospital acquired infections. Med J DY Patil Univ. 2014; 7(4): 435-438.

Bauer AW, Kirby WM, Sherris JC, Turck M. Antibiotic susceptibility testing by a standardized single disk method. Am J ClinPathol. 1966 Apr;45(4):493-496.

Bhoonderowa A, Gookool S, BiranjiaHurdoyal SD. The importance of mobile phones in the possible transmission of bacterial infections in the community. J Community Health. 2014 Oct;39(5):965-967. doi: 10.1007/s10900-014-9838-6.

Brady RR, Fraser SF, Dunlop MG, PatersonBrown S, Gibb AP. Bacterial contamination of mobile communication devices in the operative environment. J Hosp Infect. 2007 Aug;66(4):397-398. doi: 10.1016/j.jhin.2007.04.015. Available from:

http://dx.doi.org/10.1016/j.jhin.2007.0 4.015. [PubMed][Cross Ref]
Brady RR, Wasson A, Stirling I, McAllister C, Damani NN. Is your phone bugged? The incidence of bacteria known to cause nosocomial infection on healthcare workers' mobile phones. J Hosp Infect. 2006 Jan; 62(1): 123125.

Clean link. Study: Public toilet is cleaner than the average cell phone. Jul 18, 2013. [cited 2014 May 20].

Clinical and Laboratory Standards Institute. Performance standards for antimicrobial susceptibility testing; Twenty-fourth informational supplement, M100-S24. Wayne, PA: CLSI; 2014.

Elkholy M, Ewees I. Mobile (cellular) phones contamination with nosocomial pathogens in intensive care units. Med J Cairo Univ. 2010;78(2):1-5.

Forbes BA, Sahm DF, Weissfeld AS. Bailey and Scott's diagnostic microbiology. 12th ed. St Louis: Mosby; 2007.

IPAC Canada position statements and practice recommendations. Practice recommendations for infection prevention and control related to electronic devices in health care settings. Jun, 2012.

Jeske HC, Tiefenthaler W, Hohlrieder M, Hinterberger G, Benzer A. Bacterial contamination of anaesthetists' hands by personal mobile phone and fixed phone use in the operating theatre. Anaesthesia. 2007 Sep;62(9):904-906.

Kennedy KJ, Dreimanis DE, Beckingham WD, Bowden FJ. Staphylococcus aureus and stethoscopes. Med J Aust. 2003 May;178(9):468. [PubMed]

Kilic IH, Ozaslan M, Karagoz ID, Zer Y, Davutoglu V. The microbial colonisation of mobile phone used by healthcare staffs. Pak J Biol Sci. 2009 Jun $1 ; 12(11): 882-884$ doi: 10.3923/pjbs.2009.882.884. 
Kokate SB, More SR, Gujar V, Mundhe S, Zahiruddin QS. Microbiological flora of mobile phones of resident doctors. $\mathrm{J}$ Biomed Sci Eng. 2012;5:696-698. doi: 10.4236/jbise.2012.511086.

Lowy FD. Staphylococcus aureus infections. N Engl J Med. 1998 Aug;339(8):520 532. doi: 10.1056/NEJM199808203390806.

National Nosocomial Infections Surveillance (NNIS) system report, data summary from January 1992-April 2000, issued June 2000. Am J Infect Contro. 2000 Dec;28(6):429-448. doi: 10.1067/mic.2000.110544. Available from:

http://dx.doi.org/10.1067/mic.2000.11 0544. [PubMed][Cross Ref]

NCCNSC.: National Collaborating Centre for Nursing and Supportive Care (UK) 2003. Infection control-prevention of healthcare-associated infections in primary and community care. London: Thames Valley University; 2003.

Newby J. Nosocomial infection in neonates: inevitable or preventable? J Perinat Neonatal Nurs. 2008; 22(3): 221-227. doi: $\quad 10.1097 / 01 . J P N .0000333923$. 45575.04 .

Raghavendra MP, Shruthi KC, Shivalingaiah B. Bacteriological screening of hands and mobile phones of healthcare workers and its management. Int $\mathbf{J}$ Recent Trends Sci Technol. 2014;10(1):92-97.

Schultz M, Gill J, Zubairi S, Huber R, Gordin F. Bacterial contamination of computer keyboards in a teaching hospital. Infect Control Hosp Epidemiol. 2003 Apr;24(4):302-303. doi: $10.1086 / 502200$.

Singh S, Acharya S, Bhat M, Rao SK, Pentapati KC. Mobile phone hygiene: potential risks posed by use in the clinics of an Indian dental school. J Dent Educ. 2010 Oct;74(10):11531158.

Singh V, Aggarwal V, Bansal S, Garg SP, Chowdhary N. Telephone mouthpiece as a possible source of hospital infection. J Assoc Physicians India. 1998 Apr;46(4):372-373. [PubMed]

Tagoe DN, Gyande VK, Ansah EO. Bacterial Contamination of Mobile Phones: When Your Mobile Phone Could Transmit More Than Just a Call. Webmed Central Microbiology. 2011; 2(10): WMC002294.

Tambe NN, Pai C. A Study of microbial flora and MRSA harboured by mobile phones of health care personnel. Int J Recent Trends Sci Technol. 2012;4(1):14-18.

Trivedi HR, Desai KJ, Trivedi LP, Malek SS, Javdekar TB. Role of mobile phone in spreading hospital acquired infection. A study in different group of health care workers. Natl J Integr Res Med. 2011;2(3):61-66.

World Health Organization. 2011. WHO Report on the burden of endemic health care-associated infection worldwide.

http://www.who.int/iris/bitstream/106 65/80135/1/9789241501507_eng.pdf

\section{How to cite this article:}

Abhishek Padhi, Bimoch Projna Paty, Sithun Patro and Banojini Parida. 2019. Bacterial Load on Cellphones of Healthcare Givers and Patient Attendants in a Tertiary Care Hospital of Odisha- A Cross Sectional Study. Int.J.Curr.Microbiol.App.Sci. 8(03): 632-639. doi: https://doi.org/10.20546/ijcmas.2019.803.078 